\title{
Review Article \\ Influence of Gut Microbiota on Subclinical Inflammation and Insulin Resistance
}

\author{
Bruno Melo Carvalho and Mario Jose Abdalla Saad \\ Internal Medicine Department, Faculty of Medical Sciences, FCM, UNICAMP, Rua Tessália Vieira de Camargo, \\ 126 Cidade Universitária Zeferino Vaz, 13083-887 Campinas, SP, Brazil
}

Correspondence should be addressed to Mario Jose Abdalla Saad; msaad@fcm.unicamp.br

Received 3 April 2013; Accepted 16 May 2013

Academic Editor: Massimo Collino

Copyright (C) 2013 B. M. Carvalho and M. J. Abdalla Saad. This is an open access article distributed under the Creative Commons Attribution License, which permits unrestricted use, distribution, and reproduction in any medium, provided the original work is properly cited.

\begin{abstract}
Obesity is the main condition that is correlated with the appearance of insulin resistance, which is the major link among its comorbidities, such as type 2 diabetes, nonalcoholic fatty liver disease, cardiovascular and neurodegenerative diseases, and several types of cancer. Obesity affects a large number of individuals worldwide; it degrades human health and quality of life. Here, we review the role of the gut microbiota in the pathophysiology of obesity and type 2 diabetes, which is promoted by a bacterial diversity shift mediated by overnutrition. Whole bacteria, their products, and metabolites undergo increased translocation through the gut epithelium to the circulation due to degraded tight junctions and the consequent increase in intestinal permeability that culminates in inflammation and insulin resistance. Several strategies focusing on modulation of the gut microbiota (antibiotics, probiotics, and prebiotics) are being experimentally employed in metabolic derangement in order to reduce intestinal permeability, increase the production of short chain fatty acids and anorectic gut hormones, and promote insulin sensitivity to counteract the inflammatory status and insulin resistance found in obese individuals.
\end{abstract}

\section{Introduction}

Insulin resistance is the main outcome caused by nutrient overload, lipids, infections, and sepsis-induced inflammation that affects insulin-sensitive tissues, such as the liver, muscle, adipose tissue, and hypothalamus, and which also promotes defects in cell signaling pathways and homeostasis [1]. The ingestion of an unbalanced diet and low physical activity observed in recent years in the global population are the main drivers of the epidemic rates of obesity reached in the past few decades [2]. A prospective study evaluated more than 9 million people worldwide over the last three decades and observed that, globally, the average body mass index (BMI) increased by $0.4-0.5 \mathrm{~kg} / \mathrm{m}^{2}$ per decade; moreover, subregion trends showed that the average BMI increased by $1.4 \mathrm{~kg} / \mathrm{m}^{2}$ in men and $1.9 \mathrm{~kg} / \mathrm{m}^{2}$ in women, per decade [3]. However, not only developed countries such as the United States are affected by this epidemic of obesity, but also countries under development, such as Brazil and other countries, are also affected in a similar way [4].
The World Health Organization has observed that more than 1.4 billion adults are overweight and, of these, at least 200 million men and 300 million women are clinically obese [5]. Some studies have shown that the increased rate of obesity has slowed down over the last five years, trended by some specific population groups, in eastern Europe, South America, and even in some specific population groups in the United States. However, the prevalence of obesity remains high and the health costs associated with obese individuals are huge, ranging from 2 to $7 \%$ of the health budgets in high income countries, which is followed by the low income nations, while the mortality among obese people is increased $[3,6,7]$.

Obesity is characterized by chronic subclinical inflammation that affects insulin activity in its metabolically sensitive tissues, notably the liver, muscle, and adipose tissue, and drives a metabolic disorder that culminates in the deregulation of glucose homeostasis [8]. Since the observation that obese adipose tissue shows increased expression of the proinflammatory cytokine TNF- $\alpha$ [9], extensive research 
efforts have been made regarding inflammation in metabolic tissues, trying to determine what primes the insulin resistance phenomenon, the consequences of obesity, how to improve the molecular knowledge of insulin activity attenuation mediated by obesity, and how it can be managed in order to improve patient quality of life. Attempts have also been made to reduce or prevent the incidence of obesity and its comorbidities.

Here, we will focus on reviewing the latest contributions to the literature on the influence of the intestine on the pathogenesis of insulin resistance and the consequences of insulin resistance on the liver, muscle, adipose tissue, and hypothalamus, as well as the mechanisms by which the gut microbiota influences systemic insulin resistance.

\section{Intestinal Participation in Insulin Resistance}

For several decades, it has been known that the mammalians intestine harbors a great number of bacteria $\left(\sim 10^{14}\right.$ bacteria) that even surpasses the total number of cells that comprise mammalian tissues, systems, and, ultimately, the entire body [10]. Furthermore, it is estimated that the gut microbiota contains, at least, 100-fold more genes than the mammalian genome. These bacteria can live in a symbiotic way but, in certain cases, promote disease [11]. However, over the last ten years, this community that lives within the mammalian body has been gaining the status of a microbial organ that contributes to homeostasis and impacts directly on energy metabolism and insulin sensitivity $[12,13]$.

\section{The Obese Microbiome Has Increased Energy Harvesting Ability}

One of the first and foremost important observations on the role of the gut microbiota in insulin sensitivity and body weight management was observed when germ-free mice that were infected with the gut microbiota content of a conventionally raised mice showed an increase (by about $60 \%)$ in body fat content. Moreover, the occurrence of insulin resistance and glucose intolerance was seen within 14 days, even with a reduction in food intake (standard chow), providing novel evidence that the bacteria community, in some way, controlled energy metabolism [14]. Additionally, it was described that the activity of a lipoprotein lipase (LPL) suppressor, known as fasting-induced adipocyte factor (Fiaf) or angiopoietin-like protein 4 (ANGPTL4), controlled the fat storage abnormalities observed in conventionalized germ-free mice, where the gut microbiota induced selective suppression of this protein in intestinal cells and promoted an increase in LPL activity. This resulted in increased triglyceride storage in adipocytes, which was prevented upon the conventionalization of Fiaf $^{-1-}$ germ-free mice [14].

It was also shown that the resistance of germ-free mice against diet-induced obesity relied on increased liver and skeletal muscle AMPK activity and its downstream targets. This induced the activation of fatty acid oxidation and increased energy expenditure, which regulated body weight gain, since Fiaf expression in the gut epithelium was highly suppressed in germ-free mice fed a high-fat diet, keeping the body weight almost unaltered, a feature that was not maintained in Fiaf $^{-1}$ germ-free mice [15].

The great increase in interest in the relationship between the gut microbiota and mammalian metabolism has led to the utilization of very elegant and novel molecular techniques based on microbial DNA sequencing $[16,17]$. This interest has also brought new insight into the epidemic obesity rates throughout the world and the consequent incidence of type 2 diabetes, comorbidities, and cancer.

Metagenomic analyses of human volunteers showed that almost all bacteria present in the distal gut and feces belong to two main bacterial phyla, Bacteroidetes and Firmicutes [18]. The predominance of these phyla is also seen in lean mice, with a balance among the bacterial phyla, but in genetically obese $o b / o b$ mice, this balance is broken. In obese mice, a great increase in bacteria from the phylum Firmicutes and a comparable decrease in the prevalence of Bacteroidetes were observed, indicating gut microbiota alteration driven by obesity, predisposing for or associated with this metabolic condition [19]. Moreover, it was demonstrated that microbiota transplantation from ob/ob mice to germfree recipients induced a greater increase in body fat content when compared with germ-free mice that were the recipients of lean mice gut microbiota, indicating that this difference in the intestinal flora induced the obese phenotype [20]. Additionally, it was shown that the microbiota in the feces of lean and obese humans was different in a similar way as that observed in mice [20]. All this information led to the hypothesis that the gut microbiota from $o b / o b$ genetically obese mice is capable of harvesting more energy from the diet $[21,22]$, probably by the presence and/or increased prevalence of bacteria that produce enzymes that are more efficient in degrading the nutrients available in the diet.

The relationship between the phyla Bacteroidetes and Firmicutes is the main focus of discussion when obesity is studied, with a considerable amount of data showing an increase in Firmicutes prevalence and a reduction in Bacteroidetes [19, 20, 23-26]. However, this issue has not yet been completely addressed, as we can find several studies in the literature that maintain the opposite, where the prevalence of Firmicutes is decreased in overweight and obese individuals, as well as in obese mice, with an accompanying increase in Bacteroidetes prevalence [27-30]. Additionally, the presence of nonsignificant prevalent bacteria phyla in the gut of lean mice, such as Verrucomicrobia, has not been well explored until now, with very few observations on increases in pathological conditions (obesity and cancer) and no mechanistic evaluations [27, 31]. The differences observed among gut microbiota human studies still have to be addressed, evaluating the ethnics and feeding behavior of the studied population as well as the standardization of the methods used. In animal studies, the probable cause of the opposite outcomes may be a factor of different mouse strains used. The issue of the "healthy" bacterial group profile is a very important point in gut microbiota research and needs to be further explored. Thus, no proposed treatment attempting 
to induce the proliferation of certain bacterial phyla has been suggested until now.

\section{Obesity and High-Fat Diet Increase Circulating Endotoxin Levels and Activation of the Inflammatory Response}

A structural particularity of bacteria splits them into Gram positive and Gram negative, based on the cell wall structure. Each of the two most prevalent phyla belongs to one of these groups; that is, Firmicutes are Gram positive and Bacteroidetes are Gram negative bacteria. The latter group harbor lipopolysaccharides (LPS) in their cell wall, which is a large molecule formed by a lipid and a polysaccharide that elicits a strong immune response, promoting inflammation to protect the organism from bacterial infection [32]. LPS is a potent activator of pathogen-associated molecular pattern (PAMP) responses, primarily via toll-like receptor 4 (TLR4), which activates an extensive cell signaling pathway that induces the inflammatory response and cytokine expression and secretion [33] (Figure 1).

Several studies have shown that circulating levels of LPS are elevated in obese mice, rats (genetically or induced by diet), and humans. In rodents, this is directly related to increased intestinal permeability [34-36]. This phenomenon occurs due to reduced expression and activity of tight junction proteins, such as zonula occludens-1 (ZO-1) and occludin, that create, together with gut epithelial cells, a barrier that separates the intestinal lumen and its bacterial population and products from peritoneal tissues. This degradation of tight junction function leads to the leakage of bacterial products, such as LPS, and bacterial translocation, which have recently been described as key factors in both human and mice insulin resistance and inflammation $[26,35$, 37-39] (Figure 1). Recent evidence also indicates that LPS can be transported along with chylomicrons into the circulation instead of depending on epithelial injury to reach insulin sensitive organs; the inhibition of chylomicron synthesis blocks endotoxin uptake [40].

LPS is a very specific TLR4 ligand with great affinity. Its cell signaling pathway, composed of a diverse number of proteins, culminates with the inflammatory response mediated by LPS contact with cells [41-43]. Beyond the high specificity of TLR4 in identifying LPS from Gram negative bacteria, which can reach insulin sensitive tissues through the circulation from the gut and drive the inflammatory response to protect the host from bacterial infection, TLR4 has a direct role in insulin resistance mediated by obesity. LPS from the gut can react with free-fatty acids (FFA), mostly the saturated type, that are increased in the circulation of obese individuals due to an increase in adipose tissue-mediated lipolysis, de novo liver lipogenesis and ectopic lipid accumulation [44]. TLRs have been related to the gut microbiota, whereas single TLR-deficient mice, such as TLR2 ${ }^{-/-}$[26] and TLR5 ${ }^{-/-}$[45] mice, show a different microbiotic profile when compared to their control littermates. This immune modulation of the intestinal flora can induce symptoms of metabolic syndrome, such as increased body weight, blood glucose, and insulin resistance. The $\mathrm{TLR} 4^{-/-}$mice do not present an altered prevalence of gut microbiota bacteria as seen in the TLR-deficient mice cited above [46]. In obesity and conditions related to intestinal permeability, TLR4 is known to be involved in the inflammatory response that culminates in insulin resistance and metabolic derangement, as those responses are attenuated by the inhibition of this protein activity [27, 34, 47-49], such as in TLR4 loss-offunction $\mathrm{C} 3 \mathrm{H} / \mathrm{HeJ}$ mice [50], in $\mathrm{CD} 14^{-/-}$mice [51], and in $\mathrm{TLR}^{-/-}$mice [52] (Figure 1). Recent investigations have shown that fatty acids do not activate TLR4 directly, questioning the real influence of this receptor in lipid-induced insulin resistance caused by obesity $[53,54]$. Nevertheless, a hepatic protein has been identified, called fetuin-A (FetA), which is a major carrier of FFAs in the circulation [55], that acts as an endogenous ligand of TLR4, thus activating its signaling pathway, promoting insulin resistance, which was blocked in the absence of FetA, and attenuating insulin resistance induced by FFA [56]. There is evidence that shows increased FetA expression in HepG2 cells, a liver cell lineage, after treatment with thapsigargin, an ER stress inducer, in a time- and dose-dependent manner, which is blocked by pretreating the cells with 4-phenylbutyrate, a compound that inhibits ER stress [57]. These results were similar in dietinduced obese mice, which exhibited ER stress, attenuated by 4-phenylbutyrate treatment and accompanied by a reduction in FetA expression and improved insulin resistance [57]. Additionally, it was demonstrated that in obese individuals and rodents, circulating levels of FetA are increased and correlate with body weight $[58,59]$ and that body weight loss brings the FetA circulating levels back to normal in children [59]. As well, FetA ${ }^{-1-}$ mice are protected from obesity and insulin resistance induced by aging $[60,61]$.

Other PAMPs, as well as damage-associated molecular patterns (DAMPs), such as the inflammasome seem to be related to intestinal epithelial integrity. The activation of DAMPs and PAMPs in the gut is necessary for the maintenance of barrier function, while nucleotide-binding oligomerization domain protein-like receptor 3 (NLRP3) and NLRP6-deficient mice show increased intestinal permeability and increased risk of colitis [28, 62], allowing the occurrence of dysbiosis and insulin resistance and a greater possibility of nonalcoholic steatohepatitis (NASH). The inflammasome is a group of protein complexes that recognizes a wide range of bacterial, damage and stress signals; it results in caspase-1 activation and subsequent proinflammatory cytokine secretion and cell death [63]. Mice deficient in inflammasome proteins show altered gut microbiota when compared to wild-type littermates, with an increased prevalence of bacteria from the Prevotellaceae family, which is part of the Bacteroidetes phylum, and higher translocation of bacterial products from the gut to the circulation. In particular, TLR4 and TLR9 agonists induced inflammation and insulin resistance; this feature is transmissible to newborn and adult mice that come in direct contact with inflammasome-deficient animals $[28,62]$. In addition to gut microbiota modulation, inflammasome proteins are activated in macrophages by LPS, which enter into the circulation due 


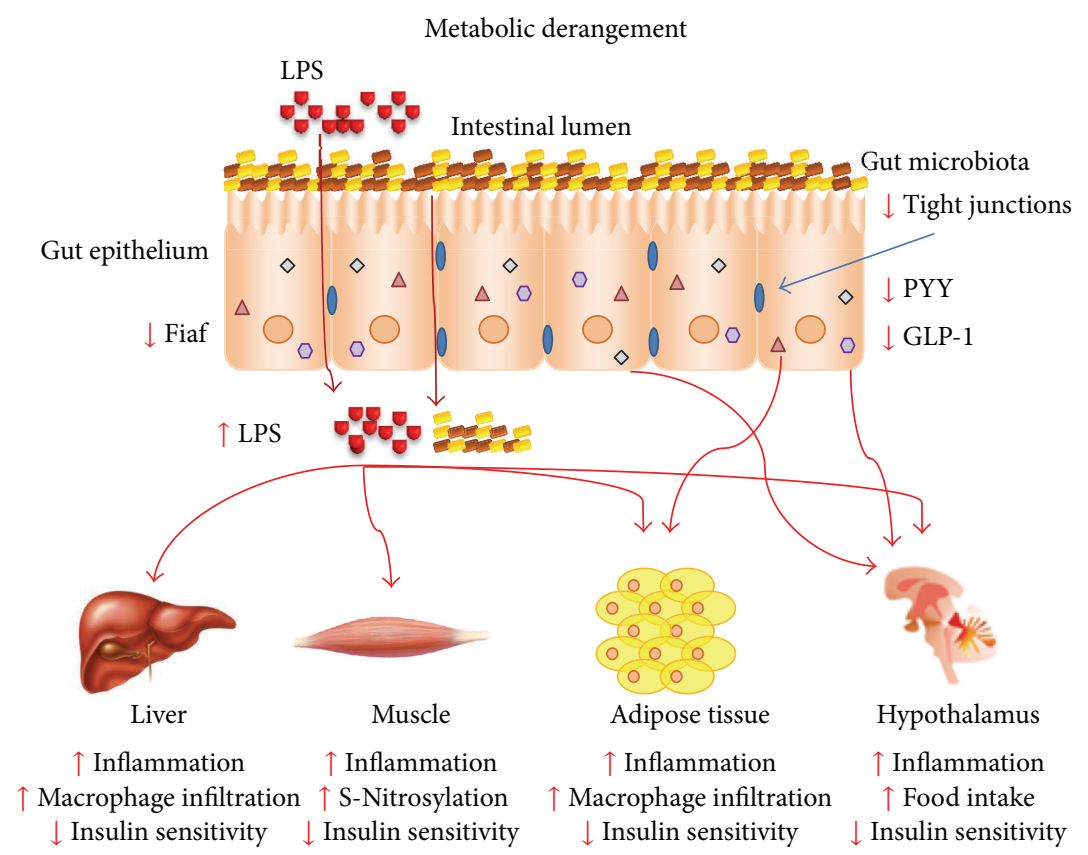

FIGURE 1: The gut microbiota is modulated by metabolic derangement, such as nutrition overload and obesity, which promote a cluster of metabolic disease-associated processes that culminate in bacterial products and whole bacteria translocation to the circulation through increased intestinal permeability caused by a reduction in tight junction expression. This triggers an immune response, inflammation, and immune cell infiltration of liver and adipose tissue. It induces insulin resistance in various tissues by diverse mechanisms and food intake deregulation in the hypothalamus promoted by the insulin and leptin resistance and also inhibited expression of gut-secreted anorectic hormones, such as GLP-1 and PYY. Additionally, there is a reduction in the intestinal Fiaf expression mediated by bacteria that deregulate the fat storage and lipid metabolism favoring the obese phenotype.

to increased intestinal permeability under obese conditions. The macrophage inflammatory activity is regulated by the TLR-induced activation of nuclear factor $\kappa \mathrm{B}(\mathrm{NF}-\kappa \mathrm{B})[64$, 65].

In addition to the bacterial immune response mediated by TLR4, viral infections also activate pattern recognition receptors (PRRs) and trigger a specific cellular signaling pathway that terminates with the activation of c-Jun $\mathrm{N}$ terminal kinase (JNK), inhibitor of nuclear factor- $\kappa \mathrm{B}$ kinase subunit $\beta$ (IKK $\beta), N F-\kappa B$, and transcription of proinflammatory cytokines, which are mediators of insulin resistance. The double-stranded RNA-activated protein kinase (PKR) is one of the molecules responsible for protection from viral infections, as it identifies double-stranded RNA (dsRNA) viruses and activates the innate immune response against these pathogens $[66,67]$. PKR is also related to obesity and insulin resistance, as its phosphorylation is increased in highfat diet fed mice, leading to activation of JNK [68] and IKK $\beta$ [69], and culminating in serine phosphorylation of IRS-1 and insulin resistance [70]; all these inflammatory features are absent or attenuated in $\mathrm{PKR}^{-/-}$mice $[71,72]$. It has been described that PKR is also activated by bacterial products, such as LPS $[73,74]$, in a dsRNA-independent way, possibly by the action of a cellular protein designated PKR-activating protein (PACT), which possesses dsRNA binding domains and interacts with other molecules that bind to PKR [75] to trigger the same signaling pathway as viral infection [76]. This could integrate the PKR signaling pathway with gut microbiota metabolic effects on insulin resistance, but has not yet been investigated (Figure 1).

The activation of inflammatory pathways by gut-derived LPS, mainly via TLR4, leads to increased expression of inducible nitric oxide synthase (iNOS) [77, 78]. In obesity, an increase in iNOS expression is also observed in insulin sensitive tissues, which promotes a phenomenon known as S-nitrosation/S-nitrosylation, where nitric oxide (NO) reacts with cysteine residues to form S-nitrosothiol adducts, thereby modulating protein function $[79,80]$. Thus, LPS induce Snitrosation/S-nitrosylation of the insulin signaling pathway (IR, IRS-1, and Akt), inducing insulin resistance in the liver, muscle, and adipose tissue in a more particular way than serine phosphorylation of IRS-1 [81-83]. The targeted disruption of iNOS and its pharmacological inhibition attenuates the Snitrosation/S-nitrosylation of insulin signaling proteins and inflammation and consequently improves insulin sensitivity [84-87] (Figure 1). Besides gut-derived LPS, other bacteria metabolites could induce S-nitrosation/S-nitrosylation of diverse proteins, modulating their activity and promoting biological effects in several tissues. Therefore, this field needs more attention and further studies.

\section{Metabolic Role of Short-Chain Fatty Acids Derived from Gut Microbiota}

The gut microbiota has an impact on mammalian physiology (mostly metabolic and immune functions) through several 
mechanisms. Some of them are discussed previously, but the gut bacteria can also interact with the host system through their metabolites, mainly short-chain fatty acids (SCFA), which are their principal end-products and are represented for the most part by acetate, propionate, and butyrate, which have physiological effects in different tissues [88]. Gut microbiota fermentation, due to anaerobic bacteria, degrades polysaccharides that are not cleaved by mammalian enzymes, in other words, nondigestible carbohydrates, to produce short-chain fatty acids and other subproducts in the cecum and colon [89]. Moreover, SCFA diversity demonstrates metabolic cooperation among the bacterial community, as no bacterial genus can hydrolyze all kinds of nutrients nor produce all metabolites found in the gut lumen [90], indicating that most of the physiological interactions of the gut microbiota with the host are not dependent on just one particular bacterial type, but the entire community.

As metabolites, SCFA have diverse effects on various cells. They are taken up by the host through passive diffusion and via mono-carboxylic acid transporters, such as monocarboxylate transporter 1 (MCT1) [91]. Primarily, they work as an energy source for colonic epithelial cells, which derive $60 \%-70 \%$ of their fuel influx from SCFA. Butyrate has a particular importance as an energy source for those cells, as almost $65 \%$ is cleared by the mucosa and more than $70 \%$ of oxygen consumption in isolated colonocytes is due to butyrate oxidation [89]. Butyrate may also play a critical role in cell growth and differentiation [92, 93]. Acetate is likely to be used as a cholesterol or fatty acid precursor, and propionate is a gluconeogenic substrate $[94,95]$. The relative levels of the specific enzymes for SCFA degradation (acetyl-CoA, propionyl-CoA, and butyryl-CoA) in different tissues are the determinants of SCFA metabolization [96]. Other molecules with metabolic regulatory functions can be released by gut bacteria, such as conjugated linoleic acids (CLA) [97, 98], which are lipid metabolites, or bile acids [99] and gases, such as methane and $\mathrm{H}_{2} \mathrm{~S}[100,101]$, but they have minor roles in mammal physiology when compared to SCFA.

SCFA also act as anti-inflammatory molecules, as acetate, propionate, and butyrate are capable of inhibiting NF- $\kappa \mathrm{B}$ activation in the host immune cells by binding to G-proteincoupled receptor, 43 and 41 (GPR43 and GPR41), thereby blocking inflammatory responses and suppressing TNF- $\alpha$ and IL- 6 release; butyrate also reduces IL-12 and increases IL-10 expression [102-105]. GPR43 seems to have great importance in mediating acetate-induced anti-inflammatory stimuli since the deletion of this gene promotes an increased inflammatory response in dextran sodium sulfate- (DSS-) induced colitis, which is attenuated by the administration of acetate in mice that express GPR43 [106]. Moreover, GPR $43^{-/-}$immune cells are hyperactive and promote an increased response to chemoattractants, such as C5a and proinflammatory cytokines [106].

Acetate and butyrate are also important in epithelial barrier function maintenance as they stimulate the production and secretion of mucus, by goblet cells, which protect the epithelium through increased expression of mucin [107]. Butyrate increases MUC-2 expression by 23 -fold in a goblet cell line in vitro, demonstrating the importance of this function in modulating intestinal permeability [108]. Butyrate also affects tight junction protein expression, that is, zonulin and occludin, and even low concentrations of this SCFA seem to reduce intestinal permeability $[109,110]$. Even with this potent mucus releasing effect by butyrate, it seems that acetate has more pronounced effects in epithelial protection, as activation of GPR43 by acetate protects mice from a lethal infection with an E. coli strain [111]. Moreover, the inhibition of GPR strongly attenuates the effects of acetate in terms of epithelial survival and integrity [112].

The products of gut microbiota fermentation, such as acetate and butyrate, are able to increase fatty acid oxidation and energy expenditure. There is evidence that acetate intake by humans promotes a reduction in body weight, circulating cholesterol, and triglyceride levels [113]. The administration of acetate or an increase in gut production mediated by the gut microbiota modulates activated $5^{\prime}$-AMP-activated protein kinase (AMPK), which inhibits acetyl-CoA carboxylase (ACC), thereby promoting fatty acid oxidation and energy expenditure [114] and leading to increased insulin sensitivity and reduced glucose intolerance in diabetic rats and in high-fat diet fed mice [27, 115]. Butyrate administration also increases AMPK activation in muscle, culminating in increased energy expenditure, as observed by an increase in brown adipose tissue mass and UCP1 expression [116].

It has been shown in cell culture experiments that shortchain fatty acids, in particular propionate and butyrate, can modulate the expression of Fiaf in intestinal cells, which was proposed as a gut microbiota mediator of fat storage [14]. Intestinal cell culture lines were exposed to short-chain fatty acids, which promoted an increase in Fiaf expression via PPAR $\gamma$ in colon cells. This was not reproduced in adipocyte cell lines, leading to the inhibition of LPL, adipogenesis and a proposed increase in fat storage mechanism control and metabolic improvement [117-119].

The activity of gut hormones in the control of appetite has been shown [120], and it is likely that the gut microbiota should interfere with the expression and activity of these hormones. Gut bacteria seem to modulate the secretion of glucagon-like peptide-1 (GLP-1), which is produced by L-cells in the colon, and peptide YY (PYY) [121], produced by ileum and colon cells, as well as leptin production by adipose tissue cells via GPR41 [122]. All of these have anorectic effects in the hypothalamus and thus promote satiety. This modulation seems to be, at least in part, mediated by the SCFA produced by fermentative bacteria. Evidence of SCFA and satiety show that an acetate infusion induces an increase in the circulating levels of GLP-1 and PYY in hyperinsulinemic overweight women [123]. Propionate reduces food intake in animal feeding studies [124-126], whereas supplementation of a dairy beverage fermented by propionic acid bacteria producer also increases satiety in humans [127]. In a similar way to propionate, butyrate induces satiety, upregulating anorectic neuropeptide expression, such as PYY and proglucagon in rat epithelial cells $[126,128]$. It is possible that these SCFA mechanisms of appetite regulation are mediated by GPR41 and dependent on the intestinal transit rate, as a deficiency in this receptor is associated with reduced PYY expression and 
faster intestinal transit with reduced energy harvesting from the diet [129]. Most of the observations on SCFA-regulated appetite are descriptive, and the mechanisms controlled by these gut microbiota-derived molecules are not yet known.

\section{Gut Microbiota Modulation}

In the last decade, a great body of evidence and knowledge about the gut microbiota and its interaction with the host, immunity, and metabolism has provided new insight regarding the influence of this forgotten "organ" on the most prevalent metabolic disease, obesity. By several mechanisms, gut bacteria influence the chronic low grade inflammation that culminates in insulin resistance and the increase in fat deposition and body weight gain, characteristic of obese individuals. With the acknowledgement of these obesity and inflammation induction mechanisms, several strategies to block or attenuate them are being developed and tested, in order to benefit obese and type 2 diabetic patients.

6.1. Antibiotic Therapy. It has been shown that the use of broad spectrum antibiotic therapy greatly modifies the gut microbiota profile in mice, improving the metabolic derangement induced by genetic obesity and/or high-fat diet feeding, but the prevalence of surviving bacteria and the benefits for the host have not been determined, as the concept of a "healthy" gut microbiota is still under investigation. The main mechanism suggested by antibiotic administration is a reduction in circulating LPS levels, which attenuates inflammation and improves the insulin resistance induced by obesity in the liver, muscle, and adipose tissue [27, 35, 130, 131]. Additionally, intestinal permeability may be reduced after the evaluation of tight junction protein expression in epithelial cells of antibiotic-treated animals, showing increased expression and function [35]. This improvement in insulin resistance was also observed in high-fat diet fed mice even in absence of a difference in body weight, which was achieved by submitting a group of animals to pair-feeding in comparison to the antibiotic-treated animals, which presented lower circulating LPS levels and TLR4 activation. This probably led to reduced intestinal permeability, leading to a reduction in JNK and IKK $\beta$ activation and reduced serine phosphorylation of IRS-1 in the liver, muscle, and adipose tissue, altogether seen as increased activation of the insulin signaling pathway, and to inhibition of macrophage infiltration into adipose tissue. Moreover, antibiotic treatment increases the portal acetate levels, which activates AMPK, fatty acid oxidation, and, possibly, energy expenditure [27]. However, even with this striking metabolic improvement in antibiotic therapy experiments, it seems that translating this strategy to humans is not the best option, as there are complex issues such as antibiotic resistance in chronic administration panels and evidence that indicates a relationship between chronic low-dose antibiotic therapy and body weight gain $[132,133]$ (Figure 2).

6.2. Probiotics. Probiotics are defined as live microorganisms that confer unspecified health benefits to the host [134].
Evidence from metagenomic profiles indicates that the obese phenotype shows an increased prevalence of Firmicutes $[20,26]$ in the gut microbiota profile, inferring a negative correlation with metabolism and insulin sensitivity. However, apart from these inconclusive observations on the "healthy" gut microbiota, the most commonly used probiotics are Lactobacillus, which belong to Firmicutes and Bifidobacterium [135]. Lactobacillus strain administration leads to several metabolic benefits in both rodents and humans, that is, a reduction in adipocyte cell size and body fat in high-fat diet fed mice [136], a reduction in fat mass and BMI, the promotion of insulin sensitivity $[137,138]$, and restriction of excessive body weight gain in the first years of life of young children [139]. Although the mechanism by which Lactobacillus control excessive adiposity has not been described, changes in fat storage genes expression, such as Fiaf, have been proposed to mediate this probiotic effect [140]. Data from Bifidobacterium administration show that the production of acetate mediates gut epithelial integrity and barrier function, protecting animals from a lethal bacterial infection [111], but no mechanism as to how acetate induces this effect has been proposed. It is tempting to suggest that acetate binding to GPR43 and its activation mediate the beneficial effects of treatment with Bifidobacterium.

A probiotic compound that has been well studied and appears in a great number of articles, named VSL\#3, composed of a blend of probiotic bacteria, modulates the gut microbiota profile [141] and shows interesting effects, such as the promotion of epithelial integrity by modulation of tight junctions [142], a reduction in inflammatory status in a chronic colitis animal model [141], protection against DSSinduced colitis, and near reversal of atherosclerotic lesions in $\mathrm{ApoE}^{-/-}$mice, which develop atherosclerosis spontaneously [143]. In a clinical trial, VSL\#3 promoted reduced intestinal permeability and improved immune activity [144]. Bacterial translocation to mesenteric adipose tissue, which seems to precede type 2 diabetes onset, is prevented by probiotic treatment. Apparently, this mechanism is mediated by acetate production and increased gut epithelial integrity [39]. It has also been shown that probiotic treatment-induced gut microbiota modulation can suppress high-fat-diet induced $\mathrm{NF}-\kappa \mathrm{B}$ activation and inflammation-induced insulin resistance [145]. Probiotics can also mimic commensal bacteria and modulate protective epithelial mucus production, reduce bacterial adhesion, increase tight junction expression, enhance epithelial and immune cell survival, induce defensins, and stimulate IgA production as well as stimulate TLRs to promote gut homeostasis [146-148] (Figure 2).

6.3. Prebiotics. Prebiotics are defined as a nonviable food component that confers a health benefit on the host associated with gut microbiota modulation [149]. The most common prebiotics used in gut microbiota modulation studies are the inulins, fructooligosaccharides, various types of galactooligosaccharides, and resistant starches. Prebiotics act by modulation of the gut microbiota profile and serve as a substrate for the production of metabolically active metabolites, in particular, SCFA, that are, acetate, propionate, 


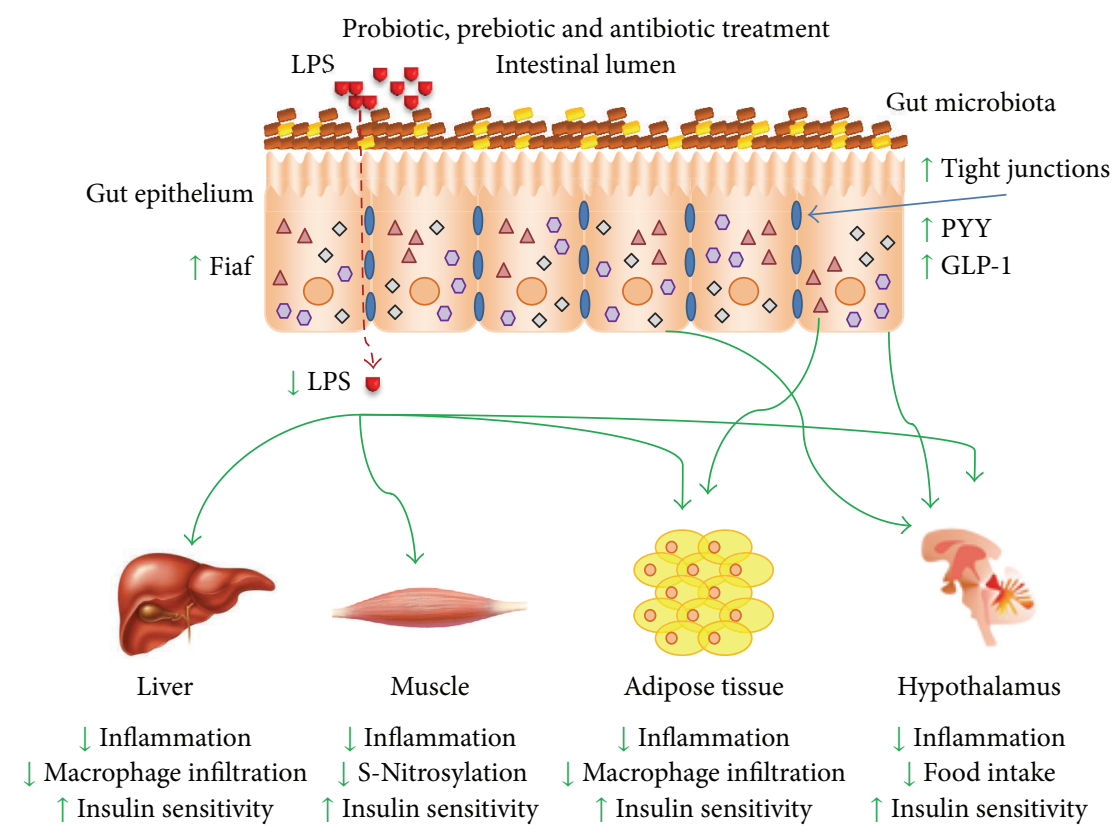

FIGURE 2: The advent of products (antibiotics, probiotics, and prebiotics) capable of modulating the gut microbiota profile, their products and metabolites (i.e., LPS, short-chain fatty acids), promotes a shift on the bacterial community prevalence, which favored the increase in tight junctions expression and function, reducing intestinal permeability and bacterial products circulation levels. Thus, the LPS circulating levels and inflammatory status in insulin-sensitive tissues are reduced, as well as muscle S-nitrosylation and liver and adipose tissue macrophage infiltration, promoting increased insulin sensitivity and the whole body metabolism. GLP-1 and PYY circulating levels are increased after treatment with gut microbiota modulators which together with the improvement in insulin sensitivity in the hypothalamus promoted reduction in food intake by satiety mechanisms and in conjunction with the increased Fiaf expression, contributed to reduce body weight.

and butyrate [150, 151]. Several studies have related prebiotic treatment to a reduction in ectopic lipid accumulation such as steatosis, reduced fat storage in white adipose tissue, in systemic inflammation, and insulin resistance in highfat diet fed and genetically obese models [152-154], and also reduced endotoxemia [155]. In clinical experiments, beneficial effects of prebiotic administration were observed, such as a reduction in BMI, waist circumference, fat mass, and insulin resistance [156-158]. The food intake regulation is another important feature of gut microbiota modulation by prebiotics, which induce gut hormone production, such as GLP-1 and PYY, that signal via anorectic pathways in the hypothalamus, and a reduction in ghrelin expression, a gastric orexigenic peptide, thereby reducing food intake $[159,160]$. Even fibers that do not change the gut microbiota profile, in a similar way to inulin-type fructans, induce food intake reduction by increasing circulating levels of GLP-1 and PYY [161-165], evidencing the important role of SCFA derived from prebiotic fermentation. Data from a 12-week prebiotic treatment in obese subjects showed a modulated gut microbiota profile, increased PYY, and decreased ghrelin circulating levels, while a single dose of prebiotics (inulin) also decreased plasma ghrelin and increased GLP-1 $[166,167]$. Prebiotics also induce the production and secretion of GLP-2 by $L$ cells; this hormone has relevant activity on gut barrier function and reduces gut permeability in obese animals [168] (Figure 2).
6.4. Bariatric Surgery. Recent data on obese subjects who have undergone gastric bypass surgery indicate that six months after the procedure, the gut microbiota profile was changed and bacteria diversity was reduced in comparison with the subjects that were obese and did not undergo the surgical procedure [169]. In addition to the changes promoted by gastric bypass, physiologically and anatomically, a number of factors could contribute to this gut profile alteration throughout this six months, primarily food intake behavior and weight loss, placing the direct influence of bariatric surgery in doubt. An early evaluation of the gut microbiota after the procedure is not viable due to the antibiotic treatment indicated for surgical recovery. Nevertheless, a recent study brought new light to this issue, where mice that underwent gastric bypass surgery presented a distinct gut microbiota profile when compared with the sham-operated mice one week after of the procedure, when no body weight difference was detected. Furthermore, the authors placed a group of mice under diet restriction to mimic the weight loss achieved by the gastric bypass group for 10-12 weeks and found that the microbiota profile was different as well, indicating that, indeed, the bariatric surgery modifies the bacterial composition of the gut [170]. In addition, they showed that gut microbiota transplantation from a shamoperated animal to germ-free mice increased adiposity as well as circulating leptin levels concomitantly with reduced food intake, as was previously demonstrated [14]. However, 
in the recipients of gut microbiota from mice that underwent gastric bypass, none of those parameters were altered when compared to germ-free mice. There was also a reduction in body weight, suggesting that the gastric bypass-associated gut microbiota may either reduce energy harvesting from the diet or produce signals to regulate energy expenditure and/or lipid metabolism in a Fiaf-independent manner since colonization of germ-free mice with either sham or gastric bypass gut microbiota inhibits Fiaf expression in intestinal cells, but this is still unknown [170]. Based on the studies cited previously, gastric bypass seems to promote gut microbiota modulation that induces beneficial effects in obese humans and rodents.

\section{Conclusions}

In summary, the literature presents incontestable data that the gut microbiota and its modulation by nutrients and excessive energy intake heavily influence glucose metabolism, lipid storage, inflammation, and insulin activity in a negative way, as observed in obesity and diabetes. Furthermore, there are intense investigations going on in this field, highlighting several strategies to modulate the gut microbiota profile to a "healthier" status in an attempt to increase insulin sensitivity by blockage of the insulin resistance inductors mediated by the interaction between bacteria and the intestinal environment of the host.

Some issues have been raised from these studies and have not been fully explored until now, such as PKR activity modulated by gut microbiota. Besides bacterial products, viruses are also found in metagenomic profiles, and viral signaling could contribute to the increased inflammation promoted by intestinal products in obesity. In a similar way, the nitrosative contribution from gut microbiota has not yet been raised as having an impact on the metabolic derangement mediated by obesity and microbial products. Also, it is unknown if attempts to ameliorate the metabolic status by gut microbiota modulation will regulate both phenomena. SCFA seem to have an important role in food intake regulation, but the mechanisms of inducing GLP-1 and PYY production in intestinal cells are still poorly described and need further investigation. Saturated fatty acids are known to promote inflammation and insulin resistance and are prevalent in the high-fat diet administered to experimental rodents in these studies and in the western diet that has led to epidemic rates of obesity. However, the utilization of unsaturated fatty acid supplementation, which is known as a lipid with antiinflammatory properties, has not yet been related to gut microbiota modulation. This is an interesting nutritional field, as probiotic and prebiotic strategies can have irrefutable benefits to the host's metabolism.

Ongoing efforts will try to determine the best set of symbiotic bacteria for mammals to harbor in the intestine in a metabolic evaluation, avoid excessive energy uptake from the diet, preserve gut barrier function, and reduce bacteria and the translocation of their inflammatory products; it is hoped that this will culminate in reduced inflammation. This issue is under debate, as articles do not show coherence regarding bacterial prevalence modulation in the gut induced by obesity and its treatment, which will need further studies and standardization. It seems that studies from different facilities bring distinct results. This issue has to be addressed in order to define what bacterial colony is more interesting to have grown in the mammalians gut.

\section{References}

[1] C. K. Glass and J. M. Olefsky, "Inflammation and lipid signaling in the etiology of insulin resistance," Cell Metabolism, vol. 15, no. 5, pp. 635-645, 2012.

[2] P. G. Kopelman, "Obesity as a medical problem," Nature, vol. 404, no. 6778, pp. 635-643, 2000.

[3] M. M. Finucane, G. A. Stevens, M. J. Cowan et al., "National, regional, and global trends in body-mass index since 1980: systematic analysis of health examination surveys and epidemiological studies with 960 country-years and 9.1 million participants," The Lancet, vol. 377, no. 9765, pp. 557-567, 2011.

[4] V. A. Ferreira and R. Magalhães, "Obesidade no Brasil: tendências atuais," Revista Portuguesa De SaúDe Pública, vol. 24, no. 2, pp. 71-91, 2006.

[5] WHO, "Obesity and overweight," Fact sheet 311, 2013, http://www.who.int/mediacentre/factsheets/fs311/en/.

[6] K. M. Flegal, M. D. Carroll, C. L. Ogden, and L. R. Curtin, "Prevalence and trends in obesity among US adults, 1999-2008," The Journal of the American Medical Association, vol. 303, no. 3, pp. 235-241, 2010.

[7] A. B. de Gonzalez, P. Hartge, J. R. Cerhan et al., "Body-mass index and mortality among 1.46 million white adults," The New England Journal of Medicine, vol. 363, no. 23, pp. 2211-2219, 2010.

[8] G. S. Hotamisligil, "Inflammation and metabolic disorders," Nature, vol. 444, no. 7121, pp. 860-867, 2006.

[9] G. S. Hotamisligil, N. S. Shargill, and B. M. Spiegelman, "Adipose expression of tumor necrosis factor- $\alpha$ : direct role in obesity-linked insulin resistance," Science, vol. 259, no. 5091, pp. 87-91, 1993.

[10] J. Qin, R. Li, J. Raes et al., "A human gut microbial gene catalogue established by metagenomic sequencing," Nature, vol. 464, no. 7285, pp. 59-65, 2010.

[11] J. Xu and J. I. Gordon, "Honor thy symbionts," Proceedings of the National Academy of Sciences of the United States of America, vol. 100, no. 18, pp. 10452-10459, 2003.

[12] V. Bocci, "The neglected organ: bacterial flora has a crucial immunostimulatory role," Perspectives in Biology and Medicine, vol. 35, no. 2, pp. 251-260, 1992.

[13] P. D. Cani and N. M. Delzenne, "The role of the gut microbiota in energy metabolism and metabolic disease," Current Pharmaceutical Design, vol. 15, no. 13, pp. 1546-1558, 2009.

[14] F. Bäckhed, H. Ding, T. Wang et al., "The gut microbiota as an environmental factor that regulates fat storage," Proceedings of the National Academy of Sciences of the United States of America, vol. 101, no. 44, pp. 15718-15723, 2004.

[15] F. Bäckhed, J. K. Manchester, C. F. Semenkovich, and J. I. Gordon, "Mechanisms underlying the resistance to diet-induced obesity in germ-free mice," Proceedings of the National Academy of Sciences of the United States of America, vol. 104, no. 3, pp. 979-984, 2007.

[16] P. B. Eckburg, E. M. Bik, C. N. Bernstein et al., "Microbiology: diversity of the human intestinal microbial flora," Science, vol. 308, no. 5728, pp. 1635-1638, 2005. 
[17] A. F. Andersson, M. Lindberg, H. Jakobsson, F. Bäckhed, P. Nyrén, and L. Engstrand, "Comparative analysis of human gut microbiota by barcoded pyrosequencing," PLOS ONE, vol. 3, no. 7, Article ID e2836, 2008.

[18] S. R. Gill, M. Pop, R. T. DeBoy et al., "Metagenomic analysis of the human distal gut microbiome," Science, vol. 312, no. 5778, pp. 1355-1359, 2006.

[19] R. E. Ley, F. Bäckhed, P. Turnbaugh, C. A. Lozupone, R. D. Knight, and J. I. Gordon, "Obesity alters gut microbial ecology," Proceedings of the National Academy of Sciences of the United States of America, vol. 102, no. 31, pp. 11070-11075, 2005.

[20] P. J. Turnbaugh, R. E. Ley, M. A. Mahowald, V. Magrini, E. R. Mardis, and J. I. Gordon, "An obesity-associated gut microbiome with increased capacity for energy harvest," Nature, vol. 444, no. 7122, pp. 1027-1031, 2006.

[21] R. P. Ferraris and R. R. Vinnakota, "Intestinal nutrient transport in genetically obese mice," The American Journal of Clinical Nutrition, vol. 62, no. 3, pp. 540-546, 1995.

[22] B. P. Warwick and D. R. Romsos, "Energy balance in adrenalectomized ob/ob mice: effects of dietary starch and glucose," The American Journal of Physiology, vol. 255, no. 1, part 2, pp. R141$\mathrm{R} 148,1988$.

[23] J. R. Mujico, G. C. Baccan, A. Gheorghe, L. E. Díaz, and A. Marcos, "Changes in gut microbiota due to supplemented fatty acids in diet-induced obese mice," The British Journal of Nutrition, 2013.

[24] J. A. Parnell and R. A. Reimer, "Prebiotic fiber modulation of the gut microbiota improves risk factors for obesity and the metabolic syndrome," Gut Microbes, vol. 3, no. 1, pp. 29-34, 2012.

[25] M. Ferrer, A. Ruiz, F. Lanza et al., "Microbiota from the distal guts of lean and obese adolescents exhibit partial functional redundancy besides clear differences in community structure," Environmental Microbiology, vol. 15, no. 1, pp. 211-226, 2013.

[26] A. M. Caricilli, P. K. Picardi, L. L. de Abreu et al., "Gut microbiota is a key modulator of insulin resistance in TLR 2 knockout mice," PLOS Biology, vol. 9, no. 12, Article ID e1001212, 2011.

[27] B. M. Carvalho, D. Guadagnini, D. M. Tsukumo et al., "Modulation of gut microbiota by antibiotics improves insulin signalling in high-fat fed mice," Diabetologia, vol. 55, no. 10, pp. 28232834, 2012.

[28] J. Henao-Mejia, E. Elinav, C. Jin et al., "Inflammasomemediated dysbiosis regulates progression of NAFLD and obesity," Nature, vol. 482, no. 7384, pp. 179-185, 2012.

[29] A. Schwiertz, D. Taras, K. Schäfer et al., "Microbiota and SCFA in lean and overweight healthy subjects," Obesity, vol. 18, no. 1, pp. 190-195, 2010.

[30] M. C. Collado, E. Isolauri, K. Laitinen, and S. Salminen, "Distinct composition of gut microbiota during pregnancy in overweight and normal-weight women," The American Journal of Clinical Nutrition, vol. 88, no. 4, pp. 894-899, 2008.

[31] J. C. Arthur, E. Perez-Chanona, M. Muhlbauer et al., "Intestinal inflammation targets cancer-inducing activity of the microbiota," Science, vol. 338, no. 6103, pp. 120-123, 2012.

[32] S. Akira and K. Takeda, "Toll-like receptor signalling," Nature Reviews Immunology, vol. 4, no. 7, pp. 499-511, 2004.

[33] R. Medzhitov and T. Horng, "Transcriptional control of the inflammatory response," Nature Reviews Immunology, vol. 9, no. 10, pp. 692-703, 2009.

[34] A. G. Oliveira, B. M. Carvalho, N. Tobar et al., "Physical exercise reduces circulating lipopolysaccharide and TLR4 activation and improves insulin signaling in tissues of DIO rats," Diabetes, vol. 60, no. 3, pp. 784-796, 2011.

[35] P. D. Cani, R. Bibiloni, C. Knauf et al., "Changes in gut microbiota control metabolic endotoxemia-induced inflammation in high-fat diet-induced obesity and diabetes in mice," Diabetes, vol. 57, no. 6, pp. 1470-1481, 2008.

[36] S. J. Creely, P. G. McTernan, C. M. Kusminski et al., "Lipopolysaccharide activates an innate immune system response in human adipose tissue in obesity and type 2 diabetes," The American Journal of Physiology, vol. 292, no. 3, pp. E740-E747, 2007.

[37] P. Brun, I. Castagliuolo, V. Di Leo et al., "Increased intestinal permeability in obese mice: new evidence in the pathogenesis of nonalcoholic steatohepatitis," The American Journal of Physiology, vol. 292, no. 2, pp. G518-G525, 2007.

[38] R. Burcelin, L. Garidou, and C. Pomie, "Immuno-microbiota cross and talk: the new paradigm of metabolic diseases," Seminars in Immunology, vol. 24, no. 1, pp. 67-74, 2012.

[39] J. Amar, C. Chabo, A. Waget et al., "Intestinal mucosal adherence and translocation of commensal bacteria at the early onset of type 2 diabetes: molecular mechanisms and probiotic treatment," EMBO Molecular Medicine, vol. 3, no. 9, pp. 559$572,2011$.

[40] S. Ghoshal, J. Witta, J. Zhong, W. de Villiers, and E. Eckhardt, "Chylomicrons promote intestinal absorption of lipopolysaccharides," Journal of Lipid Research, vol. 50, no. 1, pp. 90-97, 2009.

[41] E. Lien, T. K. Means, H. Heine et al., "Toll-like receptor 4 imparts ligand-specific recognition of bacterial lipopolysaccharide," Journal of Clinical Investigation, vol. 105, no. 4, pp. 497504,2000

[42] T. Kawai and S. Akira, "The role of pattern-recognition receptors in innate immunity: update on toll-like receptors," Nature Immunology, vol. 11, no. 5, pp. 373-384, 2010.

[43] S. I. Miller, R. K. Ernst, and M. W. Bader, "LPS, TLR4 and infectious disease diversity," Nature Reviews Microbiology, vol. 3, no. 1, pp. 36-46, 2005.

[44] V. T. Samuel and G. I. Shulman, "Mechanisms for insulin resistance: common threads and missing links," Cell, vol. 148, no. 5, pp. 852-871, 2012.

[45] M. Vijay-Kumar, J. D. Aitken, F. A. Carvalho et al., "Metabolie syndrome and altered gut microbiota in mice lacking toll-like receptor 5," Science, vol. 328, no. 5975, pp. 228-231, 2010.

[46] C. Ubeda, L. Lipuma, A. Gobourne et al., "Familial transmission rather than defective innate immunity shapes the distinct intestinal microbiota of TLR-deficient mice," Journal of Experimental Medicine, vol. 209, no. 8, pp. 1445-1456, 2012.

[47] K. L. Calisto, B. M. Carvalho, E. R. Ropelle et al., "Atorvastatin improves survival in septic rats: effect on tissue inflammatory pathway and on insulin signaling," PLoS ONE, vol. 5, no. 12, Article ID e14232, 2010.

[48] M. Milanski, G. Degasperi, A. Coope et al., "Saturated fatty acids produce an inflammatory response predominantly through the activation of TLR4 signaling in hypothalamus: implications for the pathogenesis of obesity," Journal of Neuroscience, vol. 29, no. 2, pp. 359-370, 2009.

[49] K. A. Kim, W. Gu, I. A. Lee, E. H. Joh, and D. H. Kim, "High fat diet-induced gut microbiota exacerbates inflammation and obesity in mice via the TLR4 signaling pathway," PLOS ONE, vol. 7, no. 10, Article ID e47713, 2012. 
[50] D. M. L. Tsukumo, M. A. Carvalho-Filho, J. B. C. Carvalheira et al., "Loss-of-function mutation in toll-like receptor 4 prevents diet-induced obesity and insulin resistance," Diabetes, vol. 56, no. 8, pp. 1986-1998, 2007.

[51] P. D. Cani, J. Amar, M. A. Iglesias et al., "Metabolic endotoxemia initiates obesity and insulin resistance," Diabetes, vol. 56, no. 7, pp. 1761-1772, 2007.

[52] H. Shi, M. V. Kokoeva, K. Inouye, I. Tzameli, H. Yin, and J. S. Flier, "TLR4 links innate immunity and fatty acid-induced insulin resistance," Journal of Clinical Investigation, vol. 116, no. 11, pp. 3015-3025, 2006.

[53] A. Schaeffler, P. Gross, R. Buettner et al., "Fatty acid-induced induction of toll-like receptor-4/nuclear factor- $\kappa \mathrm{B}$ pathway in adipocytes links nutritional signalling with innate immunity," Immunology, vol. 126, no. 2, pp. 233-245, 2009.

[54] C. Erridge and N. J. Samani, "Saturated fatty acids do not directly stimulate toll-like receptor signaling," Arteriosclerosis, Thrombosis, and Vascular Biology, vol. 29, no. 11, pp. 1944-1949, 2009.

[55] A. J. Cayatte, L. Kumbla, and M. T. R. Subbiah, "Marked acceleration of exogenous fatty acid incorporation into cellular triglycerides by fetuin," The Journal of Biological Chemistry, vol. 265, no. 10, pp. 5883-5888, 1990.

[56] D. Pal, S. Dasgupta, R. Kundu et al., "Fetuin-A acts as an endogenous ligand of TLR4 to promote lipid-induced insulin resistance," Nature Medicine, vol. 18, pp. 1279-1285, 2012.

[57] H. Y. Ou, H. T. Wu, H. C. Hung, Y. C. Yang, J. S. Wu, and C. J. Chang, "Endoplasmic reticulum stress induces the expression of fetuin-A to develop insulin resistance," Endocrinology, vol. 153, no. 7, pp. 2974-2984, 2012.

[58] N. A. Ismail, S. Ragab, S. M. El Dayem et al., "Fetuin-A levels in obesity: differences in relation to metabolic syndrome and correlation with clinical and laboratory variables," Archives of Medical Science, vol. 8, no. 5, pp. 826-833, 2012.

[59] T. Reinehr and C. L. Roth, "Fetuin-A and its relation to metabolic syndrome and fatty liver disease in obese children before and after weight loss," Journal of Clinical Endocrinology and Metabolism, vol. 93, no. 11, pp. 4479-4485, 2008.

[60] S. T. Mathews, G. P. Singh, M. Ranalletta et al., "Improved insulin sensitivity and resistance to weight gain in mice null for the Ahsg gene," Diabetes, vol. 51, no. 8, pp. 2450-2458, 2002.

[61] S. T. Mathews, S. Rakhade, X. Zhou, G. C. Parker, D. V. Coscina, and G. Grunberger, "Fetuin-null mice are protected against obesity and insulin resistance associated with aging," Biochemical and Biophysical Research Communications, vol. 350, no. 2, pp. 437-443, 2006.

[62] E. Elinav, T. Strowig, A. L. Kau et al., "NLRP6 inflammasome regulates colonic microbial ecology and risk for colitis," Cell, vol. 145, no. 5, pp. 745-757, 2011.

[63] T. Strowig, J. Henao-Mejia, E. Elinav, and R. Flavell, "Inflammasomes in health and disease," Nature, vol. 481, no. 7381, pp. 278-286, 2012.

[64] K. Schroder, V. Sagulenko, A. Zamoshnikova et al., "Acute lipopolysaccharide priming boosts inflammasome activation independently of inflammasome sensor induction," Immunobiology, vol. 217, no. 12, pp. 1325-1329, 2012.

[65] Y. Qiao, P. Wang, J. Qi, L. Zhang, and C. Gao, "TLR-induced NF- $\kappa$ B activation regulates NLRP3 expression in murine macrophages," FEBS Letters, vol. 586, no. 7, pp. 1022-1026, 2012.

[66] C. E. Samuel, "The eIF- $2 \alpha$ protein kinases, regulators of translation in eukaryotes from yeasts to humans," The Journal of Biological Chemistry, vol. 268, no. 11, pp. 7603-7606, 1993.
[67] M. A. García, J. Gil, I. Ventoso et al., "Impact of protein kinase PKR in cell biology: from antiviral to antiproliferative action," Microbiology and Molecular Biology Reviews, vol. 70, no. 4, pp. 1032-1060, 2006.

[68] J. Hirosumi, G. Tuncman, L. Chang et al., "A central, role for JNK in obesity and insulin resistance," Nature, vol. 420, no. 6913, pp. 333-336, 2002.

[69] M. C. Arkan, A. L. Hevener, F. R. Greten et al., "IKK- $\beta$ links inflammation to obesity-induced insulin resistance," Nature Medicine, vol. 11, no. 2, pp. 191-198, 2005.

[70] V. Aguirre, E. D. Werner, J. Giraud, Y. H. Lee, S. E. Shoelson, and M. F. White, "Phosphorylation of Ser307 in insulin receptor substrate-1 blocks interactions with the insulin receptor and inhibits insulin action," The Journal of Biological Chemistry, vol. 277, no. 2, pp. 1531-1537, 2002.

[71] T. Nakamura, M. Furuhashi, P. Li et al., "Double-stranded RNAdependent protein kinase links pathogen sensing with stress and metabolic homeostasis," Cell, vol. 140, no. 3, pp. 338-348, 2010.

[72] M. A. Carvalho-Filho, B. M. Carvalho, A. G. Oliveira et al., "Double-stranded RNA-activated protein kinase is a key modulator of insulin sensitivity in physiological conditions and in obesity in mice," Endocrinology, vol. 153, no. 11, pp. 5261-5274, 2012.

[73] L. C. Hsu, J. M. Park, K. Zhang et al., “The protein kinase PKR is required for macrophage apoptosis after activation of toll-like receptor 4," Nature, vol. 428, no. 6980, pp. 341-345, 2004.

[74] M. Cabanski, M. Steinmüller, L. M. Marsh, E. Surdziel, W. Seeger, and J. Lohmeyer, "PKR regulates TLR2/TLR4dependent signaling in murine alveolar macrophages," The American Journal of Respiratory Cell and Molecular Biology, vol. 38, no. 1, pp. 26-31, 2008.

[75] G. A. Peters, R. Hartmann, J. Qin, and G. C. Sen, "Modular structure of PACT: distinct domains for binding and activating PKR," Molecular and Cellular Biology, vol. 21, no. 6, pp. 19081920, 2001.

[76] B. R. Williams, “Signal integration via PKR,” Science's STKE, vol. 2001, no. 89, p. RE2, 2001.

[77] S. Symeonides and R. A. Balk, "Nitric oxide in the pathogenesis of sepsis," Infectious Disease Clinics of North America, vol. 13, no. 2, pp. 449-463, 1999.

[78] H. Sugita, M. Kaneki, E. Tokunaga et al., "Inducible nitric oxide synthase plays a role in LPS-induced hyperglycemia and insulin resistance," The American Journal of Physiology, vol. 282, no. 2, pp. E386-E394, 2002.

[79] J. S. Stamler, D. I. Simon, J. A. Osborne et al., "S-nitrosylation of proteins with nitric oxide: synthesis and characterization of biologically active compounds," Proceedings of the National Academy of Sciences of the United States of America, vol. 89, no. 1, pp. 444-448, 1992.

[80] J. S. Stamler, E. J. Toone, S. A. Lipton, and N. J. Sucher, "(S)NO signals: translocation, regulation, and a consensus motif," Neuron, vol. 18, no. 5, pp. 691-696, 1997.

[81] S. Shinozaki, C. S. Choi, N. Shimizu et al., "Liver-specific inducible nitric-oxide synthase expression is sufficient to cause hepatic insulin resistance and mild hyperglycemia in mice," The Journal of Biological Chemistry, vol. 286, no. 40, pp. 3495934975, 2011.

[82] M. A. Carvalho-Filho, M. Ueno, S. M. Hirabara et al., "Snitrosation of the insulin receptor, insulin receptor substrate 1 , and protein kinase B/Akt: a novel mechanism of insulin resistance," Diabetes, vol. 54, no. 4, pp. 959-967, 2005. 
[83] H. Ovadia, Y. Haim, O. Nov et al., "Increased adipocyte Snitrosylation targets anti-lipolytic action of insulin: relevance to adipose tissue dysfunction in obesity," The Journal of Biological Chemistry, vol. 286, no. 35, pp. 30433-30443, 2011.

[84] M. A. Carvalho-Filho, M. Ueno, J. B. C. Carvalheira, L. A. Velloso, and M. J. A. Saad, "Targeted disruption of iNOS prevents LPS-induced S-nitrosation of IR $\beta /$ IRS- 1 and Akt and insulin resistance in muscle of mice," The American Journal of Physiology, vol. 291, no. 3, pp. E476-E482, 2006.

[85] E. R. Ropelle, J. R. Pauli, D. E. Cintra et al., “Targeted disruption of inducible nitric oxide synthase protects against aging, Snitrosation, and insulin resistance in muscle of male mice," Diabetes, vol. 62, no. 2, pp. 466-470, 2013.

[86] J. R. Pauli, E. R. Ropelle, D. E. Cintra et al., "Acute physical exercise reverses S-nitrosation of the insulin receptor, insulin receptor substrate 1 and protein kinase B/Akt in diet-induced obese Wistar rats," Journal of Physiology, vol. 586, no. 2, pp. 659671, 2008.

[87] M. A. Carvalho-Filho, E. R. Ropelle, R. J. Pauli et al., "Aspirin attenuates insulin resistance in muscle of diet-induced obese rats by inhibiting inducible nitric oxide synthase production and S-nitrosylation of IR $\beta$ /IRS-1 and Akt," Diabetologia, vol. 52, no. 11, pp. 2425-2434, 2009.

[88] G. T. Macfarlane and S. Macfarlane, "Fermentation in the human large intestine: its physiologic consequences and the potential contribution of prebiotics," Journal of Clinical Gastroenterology, vol. 45, pp. S120-S127, 2011.

[89] J. H. Cummings, E. W. Pomare, W. J. Branch, C. P. E. Naylor, and G. T. Macfarlane, "Short chain fatty acids in human large intestine, portal, hepatic and venous blood," Gut, vol. 28, no. 10, pp. 1221-1227, 1987.

[90] P. Louis and H. J. Flint, "Diversity, metabolism and microbial ecology of butyrate-producing bacteria from the human large intestine," FEMS Microbiology Letters, vol. 294, no. 1, pp. 1-8, 2009.

[91] P. Louis, K. P. Scott, S. H. Duncan, and H. J. Flint, "Understanding the effects of diet on bacterial metabolism in the large intestine," Journal of Applied Microbiology, vol. 102, no. 5, pp. 1197-1208, 2007.

[92] M. S. M. Ardawi and E. A. Newsholme, "Fuel utilization in colonocytes of the rat," Biochemical Journal, vol. 231, no. 3, pp. 713-719, 1985.

[93] W. E. Roediger, "Short chain fatty acids as metabolic regulators of ion absorption in the colon," Acta Veterinaria Scandinavica Supplementum, vol. 86, pp. 116-125, 1989.

[94] N. M. Delzenne and C. M. Williams, "Prebiotics and lipid metabolism," Current Opinion in Lipidology, vol. 13, no. 1, pp. 61-67, 2002.

[95] S. H. Al-Lahham, M. P. Peppelenbosch, H. Roelofsen, R. J. Vonk, and K. Venema, "Biological effects of propionic acid in humans; metabolism, potential applications and underlying mechanisms," Biochimica et Biophysica Acta, vol. 1801, no. 11, pp. 1175-1183, 2010.

[96] M. Elia and J. H. Cummings, "Physiological aspects of energy metabolism and gastrointestinal effects of carbohydrates," European Journal of Clinical Nutrition, vol. 61, supplement 1, pp. S40S74, 2007.

[97] E. Devillard, F. M. McIntosh, S. H. Duncan, and R. J. Wallace, "Metabolism of linoleic acid by human gut bacteria: different routes for biosynthesis of conjugated linoleic acid," Journal of Bacteriology, vol. 189, no. 6, pp. 2566-2570, 2007.
[98] S. Kishino, J. Ogawa, K. Yokozeki, and S. Shimizu, "Metabolic diversity in biohydrogenation of polyunsaturated fatty acids by lactic acid bacteria involving conjugated fatty acid production," Applied Microbiology and Biotechnology, vol. 84, no. 1, pp. 87-97, 2009.

[99] J. R. Swann, E. J. Want, F. M. Geier et al., "Systemic gut microbial modulation of bile acid metabolism in host tissue compartments," Proceedings of the National Academy of Sciences of the United States of America, vol. 108, no. 1, pp. 4523-4530, 2011.

[100] A. B. Sahakian, S. R. Jee, and M. Pimentel, "Methane and the gastrointestinal tract," Digestive Diseases and Sciences, vol. 55, no. 8, pp. 2135-2143, 2010.

[101] P. Marquet, S. H. Duncan, C. Chassard, A. Bernalier-Donadille, and H. J. Flint, "Lactate has the potential to promote hydrogen sulphide formation in the human colon," FEMS Microbiology Letters, vol. 299, no. 2, pp. 128-134, 2009.

[102] S. Tedelind, F. Westberg, M. Kjerrulf, and A. Vidal, "Antiinflammatory properties of the short-chain fatty acids acetate and propionate: a study with relevance to inflammatory bowel disease," World Journal of Gastroenterology, vol. 13, no. 20, pp. 2826-2832, 2007.

[103] S. H. Al-Lahham, H. Roelofsen, M. Priebe et al., "Regulation of adipokine production in human adipose tissue by propionic acid," European Journal of Clinical Investigation, vol. 40, no. 5, pp. 401-407, 2010.

[104] J. Fukae, Y. Amasaki, Y. Yamashita et al., "Butyrate suppresses tumor necrosis factor $\alpha$ production by regulating specific messenger RNA degradation mediated through a cis-acting AU-rich element," Arthritis and Rheumatism, vol. 52, no. 9, pp. 2697-2707, 2005.

[105] M. D. Säemann, G. A. Böhmig, C. H. Osterreicher et al., "Antiinflammatory effects of sodium butyrate on human monocytes: potent inhibition of IL-12 and up-regulation of IL-10 production," The FASEB Journal, vol. 14, no. 15, pp. 2380-2382, 2000.

[106] K. M. Maslowski, A. T. Vieira, A. Ng et al., "Regulation of inflammatory responses by gut microbiota and chemoattractant receptor GPR43," Nature, vol. 461, no. 7268, pp. 1282-1286, 2009.

[107] A. Barcelo, J. Claustre, F. Moro, J. A. Chayvialle, J. C. Cuber, and P. Plaisancié, "Mucin secretion is modulated by luminal factors in the isolated vascularly perfused rat colon," Gut, vol. 46, no. 2, pp. 218-224, 2000.

[108] E. Gaudier, A. Jarry, H. M. Blottière et al., "Butyrate specifically modulates MUC gene expression in intestinal epithelial goblet cells deprived of glucose," The American Journal of Physiology, vol. 287, no. 6, pp. G1168-G1174, 2004.

[109] M. Bordin, F. D’Atri, L. Guillemot, and S. Citi, "Histone deacetylase inhibitors up-regulate the expression of tight junction proteins," Molecular Cancer Research, vol. 2, no. 12, pp. 692-701, 2004.

[110] L. Peng, Z. He, W. Chen, I. R. Holzman, and J. Lin, "Effects of butyrate on intestinal barrier function in a caco-2 cell monolayer model of intestinal barrier," Pediatric Research, vol. 61, no. 1, pp. 37-41, 2007.

[111] S. Fukuda, H. Toh, K. Hase et al., "Bifidobacteria can protect from enteropathogenic infection through production of acetate," Nature, vol. 469, no. 7331, pp. 543-547, 2011.

[112] T. Suzuki, S. Yoshida, and H. Hara, "Physiological concentrations of short-chain fatty acids immediately suppress colonic epithelial permeability," The British Journal of Nutrition, vol. 100, no. 2, pp. 297-305, 2008. 
[113] T. Kondo, M. Kishi, T. Fushimi, S. Ugajin, and T. Kaga, "Vinegar intake reduces body weight, body fat mass, and serum triglyceride levels in obese Japanese subjects," Bioscience, Biotechnology and Biochemistry, vol. 73, no. 8, pp. 1837-1843, 2009.

[114] B. B. Kahn, T. Alquier, D. Carling, and D. G. Hardie, "AMPactivated protein kinase: ancient energy gauge provides clues to modern understanding of metabolism," Cell Metabolism, vol. 1, no. 1, pp. 15-25, 2005.

[115] S. Sakakibara, T. Yamauchi, Y. Oshima, Y. Tsukamoto, and T. Kadowaki, "Acetic acid activates hepatic AMPK and reduces hyperglycemia in diabetic KK-A(y) mice," Biochemical and Biophysical Research Communications, vol. 344, no. 2, pp. 597604, 2006.

[116] Z. Gao, J. Yin, J. Zhang et al., "Butyrate improves insulin sensitivity and increases energy expenditure in mice," Diabetes, vol. 58, no. 7, pp. 1509-1517, 2009.

[117] C. Grootaert, T. van de Wiele, I. van Roosbroeck et al., "Bacterial monocultures, propionate, butyrate and $\mathrm{H}_{2} \mathrm{O}_{2}$ modulate the expression, secretion and structure of the fasting-induced adipose factor in gut epithelial cell lines," Environmental Microbiology, vol. 13, no. 7, pp. 1778-1789, 2011.

[118] S. Alex, K. Lange, T. Amolo et al., "Short-chain fatty acids stimulate angiopoietin-like 4 synthesis in human colon adenocarcinoma cells by activating peroxisome proliferator-activated receptor $\gamma$," Molecular and Cellular Biology, vol. 33, no. 7, pp. 1303-1316, 2013.

[119] Y. H. Hong, Y. Nishimura, D. Hishikawa et al., "Acetate and propionate short chain fatty acids stimulate adipogenesis via GPCR43," Endocrinology, vol. 146, no. 12, pp. 5092-5099, 2005.

[120] C. J. Small and S. R. Bloom, "Gut hormones and the control of appetite," Trends in Endocrinology and Metabolism, vol. 15, no. 6, pp. 259-263, 2004.

[121] O. B. Chaudhri, V. Salem, K. G. Murphy, and S. R. Bloom, "Gastrointestinal satiety signals," Annual Review of Physiology, vol. 70, pp. 239-255, 2008.

[122] Y. Xiong, N. Miyamoto, K. Shibata et al., "Short-chain fatty acids stimulate leptin production in adipocytes through the $G$ protein-coupled receptor GPR41," Proceedings of the National Academy of Sciences of the United States of America, vol. 101, no. 4, pp. 1045-1050, 2004.

[123] K. R. Freeland and T. M. S. Wolever, "Acute effects of intravenous and rectal acetate on glucagon-like peptide-1, peptide YY, ghrelin, adiponectin and tumour necrosis factor- $\alpha$," The British Journal of Nutrition, vol. 103, no. 3, pp. 460-466, 2010.

[124] C. A. Baile, "Metabolites as feedbacks for control of feed intake and receptor sites in goats and sheep," Physiology and Behavior, vol. 7, no. 6, pp. 819-826, 1971.

[125] M. H. Anil and J. M. Forbes, "Feeding in sheep during intraportal infusions of short-chain fatty acids and the effect of liver denervation," Journal of Physiology, vol. 298, pp. 407-414, 1980.

[126] H. V. Lin, A. Frassetto, E. J. Kowalik Jr. et al., "Butyrate and propionate protect against diet-induced obesity and regulate gut hormones via free fatty acid receptor 3-independent mechanisms," PLoS ONE, vol. 7, no. 4, Article ID e35240, 2012.

[127] R. M. A. J. Ruijschop, A. E. M. Boelrijk, and M. C. T. Giffel, "Satiety effects of a dairy beverage fermented with propionic acid bacteria," International Dairy Journal, vol. 18, no. 9, pp. 945950, 2008.
[128] J. Zhou, M. Hegsted, K. L. McCutcheon et al., "Peptide YY and proglucagon mRNA expression patterns and regulation in the gut," Obesity, vol. 14, no. 4, pp. 683-689, 2006.

[129] B. S. Samuel, A. Shaito, T. Motoike et al., "Effects of the gut microbiota on host adiposity are modulated by the shortchain fatty-acid binding G protein-coupled receptor, Gpr41," Proceedings of the National Academy of Sciences of the United States of America, vol. 105, no. 43, pp. 16767-16772, 2008.

[130] M. Membrez, F. Blancher, M. Jaquet et al., "Gut microbiota modulation with norfloxacin and ampicillin enhances glucose tolerance in mice," The FASEB Journal, vol. 22, no. 7, pp. 24162426, 2008.

[131] C. J. Chou, M. Membrez, and F. Blancher, "Gut decontamination with norfloxacin and ampicillin enhances insulin sensitivity in mice," Nestle Nutrition Workshop Series: Pediatric Program, vol. 62, pp. 127-140, 2008.

[132] I. Cho, S. Yamanishi, L. Cox et al., "Antibiotics in early life alter the murine colonic microbiome and adiposity," Nature, vol. 488, no. 7413, pp. 621-626, 2012.

[133] G. Ternak, "Antibiotics may act as growth/obesity promoters in humans as an inadvertent result of antibiotic pollution?" Medical Hypotheses, vol. 64, no. 1, pp. 14-16, 2005.

[134] M. Caselli, F. Cassol, G. Calò, J. Holton, G. Zuliani, and A. Gasbarrini, "Actual concept of "probiotics": is it more functional to science or business?" World Journal of Gastroenterology, vol. 19, no. 10, pp. 1527-1540, 2013.

[135] L. Macia, A. N. Thorburn, L. C. Binge et al., "Microbial influences on epithelial integrity and immune function as a basis for inflammatory diseases," Immunological Reviews, vol. 245, no. 1, pp. 164-176, 2012.

[136] N. Takemura, T. Okubo, and K. Sonoyama, "Lactobacillus plantarum strain No. 14 reduces adipocyte size in mice fed highfat diet," Experimental Biology and Medicine, vol. 235, no. 7, pp. 849-856, 2010.

[137] Y. Kadooka, M. Sato, K. Imaizumi et al., "Regulation of abdominal adiposity by probiotics (Lactobacillus gasseri SBT2055) in adults with obese tendencies in a randomized controlled trial," European Journal of Clinical Nutrition, vol. 64, no. 6, pp. 636643, 2010.

[138] A. S. Andreasen, N. Larsen, T. Pedersen-Skovsgaard et al., "Effects of Lactobacillus acidophilus NCFM on insulin sensitivity and the systemic inflammatory response in human subjects," The British Journal of Nutrition, vol. 104, no. 12, pp. 1831-1838, 2010.

[139] R. Luoto, M. Kalliomäki, K. Laitinen, and E. Isolauri, “The impact of perinatal probiotic intervention on the development of overweight and obesity: follow-up study from birth to 10 years," International Journal of Obesity, vol. 34, no. 10, pp. 15311537, 2010.

[140] L. Aronsson, Y. Huang, P. Parini et al., "Decreased fat storage by Lactobacillus paracasei is associated with increased levels of angiopoietin-like 4 protein (ANGPTL4)," PLoS ONE, vol. 5, no. 9, Article ID e13087, 2010.

[141] J. M. Uronis, J. C. Arthur, T. Keku et al., "Gut microbial diversity is reduced by the probiotic VSL\#3 and correlates with decreased TNBS-induced colitis," Inflammatory Bowel Diseases, vol. 17, no. 1, pp. 289-297, 2011.

[142] R. Mennigen, K. Nolte, E. Rijcken et al., "Probiotic mixture VSL\#3 protects the epithelial barrier by maintaining tight junction protein expression and preventing apoptosis in a murine model of colitis," The American Journal of Physiology, vol. 296, no. 5, pp. G1140-G1149, 2009. 
[143] A. Mencarelli, S. Cipriani, B. Renga et al., "VSL\#3 resets insulin signaling and protects against NASH and atherosclerosis in a model of genetic dyslipidemia and intestinal inflammation," PLoS ONE, vol. 7, no. 9, Article ID e45425, 2012.

[144] C. Alberda, L. Gramlich, J. Meddings et al., "Effects of probiotic therapy in critically ill patients: a randomized, double-blind, placebo-controlled trial," The American Journal of Clinical Nutrition, vol. 85, no. 3, pp. 816-823, 2007.

[145] X. Ma, J. Hua, and Z. Li, "Probiotics improve high fat dietinduced hepatic steatosis and insulin resistance by increasing hepatic NKT cells," Journal of Hepatology, vol. 49, no. 5, pp. 821830, 2008.

[146] S. Rakoff-Nahoum, J. Paglino, F. Eslami-Varzaneh, S. Edberg, and R. Medzhitov, "Recognition of commensal microflora by toll-like receptors is required for intestinal homeostasis," Cell, vol. 118, no. 2, pp. 229-241, 2004.

[147] S. Resta-Lenert and K. E. Barrett, "Live probiotics protect intestinal epithelial cells from the effects of infection with enteroinvasive Escherichia coli (EIEC)," Gut, vol. 52, no. 7, pp. 988-997, 2003.

[148] A. A. Zyrek, C. Cichon, S. Helms, C. Enders, U. Sonnenborn, and M. A. Schmidt, "Molecular mechanisms underlying the probiotic effects of Escherichia coli Nissle 1917 involve ZO-2 and

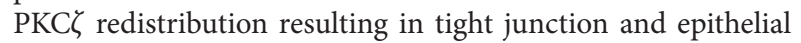
barrier repair," Cellular Microbiology, vol. 9, no. 3, pp. 804-816, 2007.

[149] M. Pineiro, N. G. Asp, G. Reid et al., "FAO Technical meeting on prebiotics," Journal of Clinical Gastroenterology, vol. 42, supplement 3, part 2, pp. S156-S159, 2008.

[150] A. M. Bakker-Zierikzee, E. A. F. van Tol, H. Kroes, M. S. Alles, F. J. Kok, and J. G. Bindels, "Faecal SIgA secretion in infants fed on pre- or probiotic infant formula," Pediatric Allergy and Immunology, vol. 17, no. 2, pp. 134-140, 2006.

[151] F. Campeotto, A. Suau, N. Kapel et al., "A fermented formula in pre-term infants: clinical tolerance, gut microbiota, downregulation of faecal calprotectin and up-regulation of faecal secretory IgA," The British Journal of Nutrition, vol. 105, no. 12, pp. 1843-1851, 2011.

[152] P. D. Cani, C. Knauf, M. A. Iglesias, D. J. Drucker, N. M. Delzenne, and R. Burcelin, "Improvement of glucose tolerance and hepatic insulin sensitivity by oligofructose requires a functional glucagon-like peptide 1 receptor," Diabetes, vol. 55, no. 5, pp. 1484-1490, 2006.

[153] P. D. Cam, A. M. Neyrinck, N. Maton, and N. M. Delzenne, "Oligofructose promotes satiety in rats fed a high-fat diet: involvement of glucagon-like peptide," Obesity Research, vol. 13, no. 6, pp. 1000-1007, 2005.

[154] C. Daubioul, N. Rousseau, R. Demeure et al., "Dietary fructans, but not cellulose, decrease triglyceride accumulation in the liver of obese Zucker fa/fa rats," Journal of Nutrition, vol. 132, no. 5, pp. 967-973, 2002.

[155] P. D. Cani, A. M. Neyrinck, F. Fava et al., "Selective increases of bifidobacteria in gut microflora improve high-fat-diet-induced diabetes in mice through a mechanism associated with endotoxaemia," Diabetologia, vol. 50, no. 11, pp. 2374-2383, 2007.

[156] S. A. Abrams, I. J. Griffin, K. M. Hawthorne, and K. J. Ellis, "Effect of prebiotic supplementation and calcium intake on body mass index," Journal of Pediatrics, vol. 151, no. 3, pp. $293-$ 298, 2007.

[157] S. Genta, W. Cabrera, N. Habib et al., "Yacon syrup: beneficial effects on obesity and insulin resistance in humans," Clinical Nutrition, vol. 28, no. 2, pp. 182-187, 2009.
[158] M. Roberfroid, G. R. Gibson, L. Hoyles et al., "Prebiotic effects: metabolic and health benefits," The British Journal of Nutrition, vol. 104, supplement 2, pp. S1-S63, 2010.

[159] P. D. Cani, S. Hoste, Y. Guiot, and N. M. Delzenne, "Dietary non-digestible carbohydrates promote L-cell differentiation in the proximal colon of rats," The British Journal of Nutrition, vol. 98, no. 1, pp. 32-37, 2007.

[160] N. M. Delzenne, P. D. Cani, C. Daubioul, and A. M. Neyrinck, "Impact of inulin and oligofructose on gastrointestinal peptides," The British Journal of Nutrition, vol. 93, pp. S157-S161, 2005.

[161] J. M. Gee and I. T. Johnson, "Dietary lactitol fermentation increases circulating peptide YY and glucagon-like peptide- 1 in rats and humans," Nutrition, vol. 21, no. 10, pp. 1036-1043, 2005.

[162] A. A. Aziz, L. S. Kenney, B. Goulet, and E. S. Abdel-Aal, "Dietary starch type affects body weight and glycemic control in freely fed but not energy-restricted obese rats," Journal of Nutrition, vol. 139, no. 10, pp. 1881-1889, 2009.

[163] M. J. Keenan, J. Zhou, K. L. McCutcheon et al., "Effects of resistant starch, a non-digestible fermentable fiber, on reducing body fat," Obesity, vol. 14, no. 9, pp. 1523-1534, 2006.

[164] L. Shen, M. J. Keenan, R. J. Martin et al., "Dietary resistant starch increases hypothalamic POMC expression in rats," Obesity, vol. 17, no. 1, pp. 40-45, 2009.

[165] J. Zhou, R. J. Martin, R. T. Tulley et al., "Dietary resistant starch upregulates total GLP-1 and PYY in a sustained daylong manner through fermentation in rodents," The American Journal of Physiology, vol. 295, no. 5, pp. E1160-E1166, 2008.

[166] J. A. Parnell and R. A. Reimer, "Weight loss during oligofructose supplementation is associated with decreased ghrelin and increased peptide YY in overweight and obese adults," The American Journal of Clinical Nutrition, vol. 89, no. 6, pp. 17511759, 2009.

[167] J. Tarini and T. M. S. Wolever, "The fermentable fibre inulin increases postprandial serum short-chain fatty acids and reduces free-fatty acids and ghrelin in healthy subjects," Applied Physiology, Nutrition and Metabolism, vol. 35, no. 1, pp. 9-16, 2010.

[168] P. D. Cani, S. Possemiers, T. van de Wiele et al., "Changes in gut microbiota control inflammation in obese mice through a mechanism involving GLP-2-driven improvement of gut permeability," Gut, vol. 58, no. 8, pp. 1091-1103, 2009.

[169] H. Zhang, J. K. DiBaise, A. Zuccolo et al., "Human gut microbiota in obesity and after gastric bypass," Proceedings of the National Academy of Sciences of the United States of America, vol. 106, no. 7, pp. 2365-2370, 2009.

[170] A. P. Liou, M. Paziuk, J. M. Luevano Jr., S. Machineni, P. J. Turnbaugh, and L. M. Kaplan, "Conserved shifts in the gut microbiota due to gastric bypass reduce host weight and adiposity," Science Translational Medicine, vol. 5, no. 178, Article ID 178ral41, 2013. 


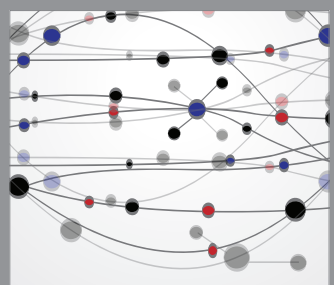

The Scientific World Journal
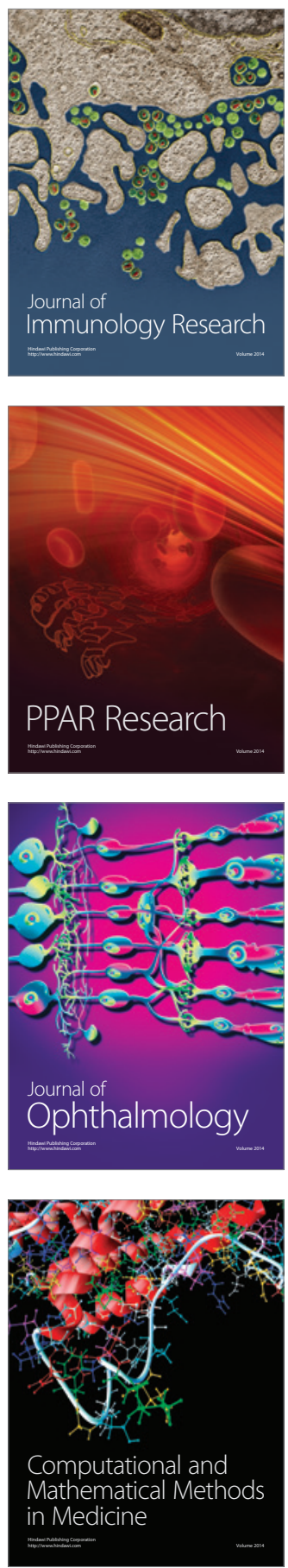

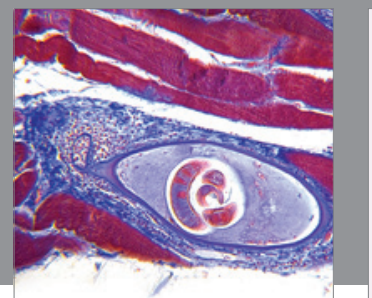

Gastroenterology

Research and Practice
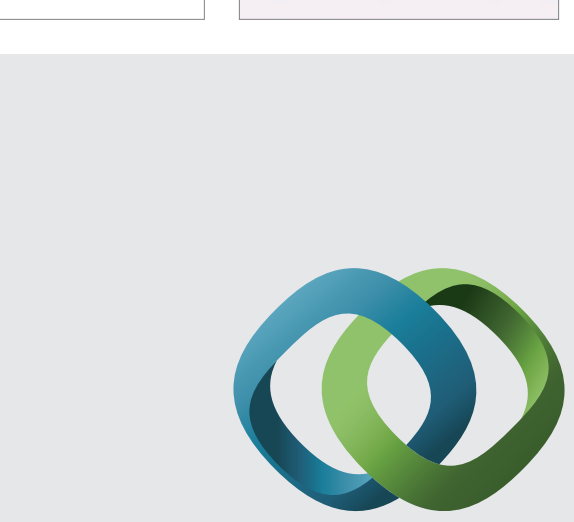

\section{Hindawi}

Submit your manuscripts at

http://www.hindawi.com
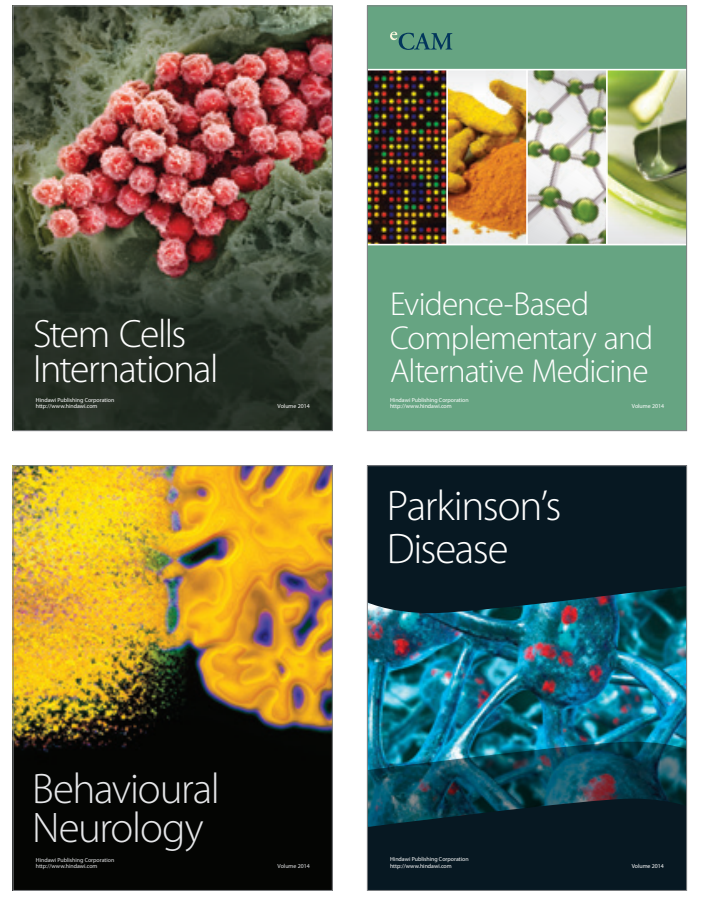
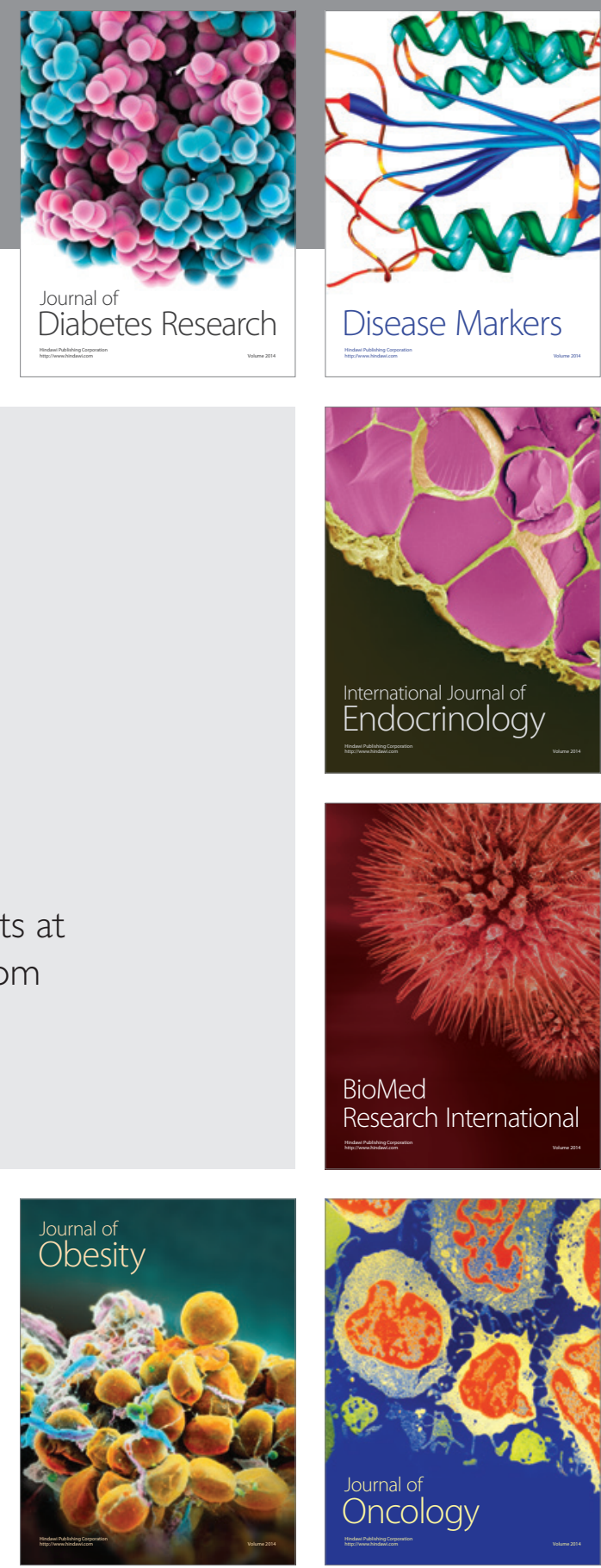

Disease Markers
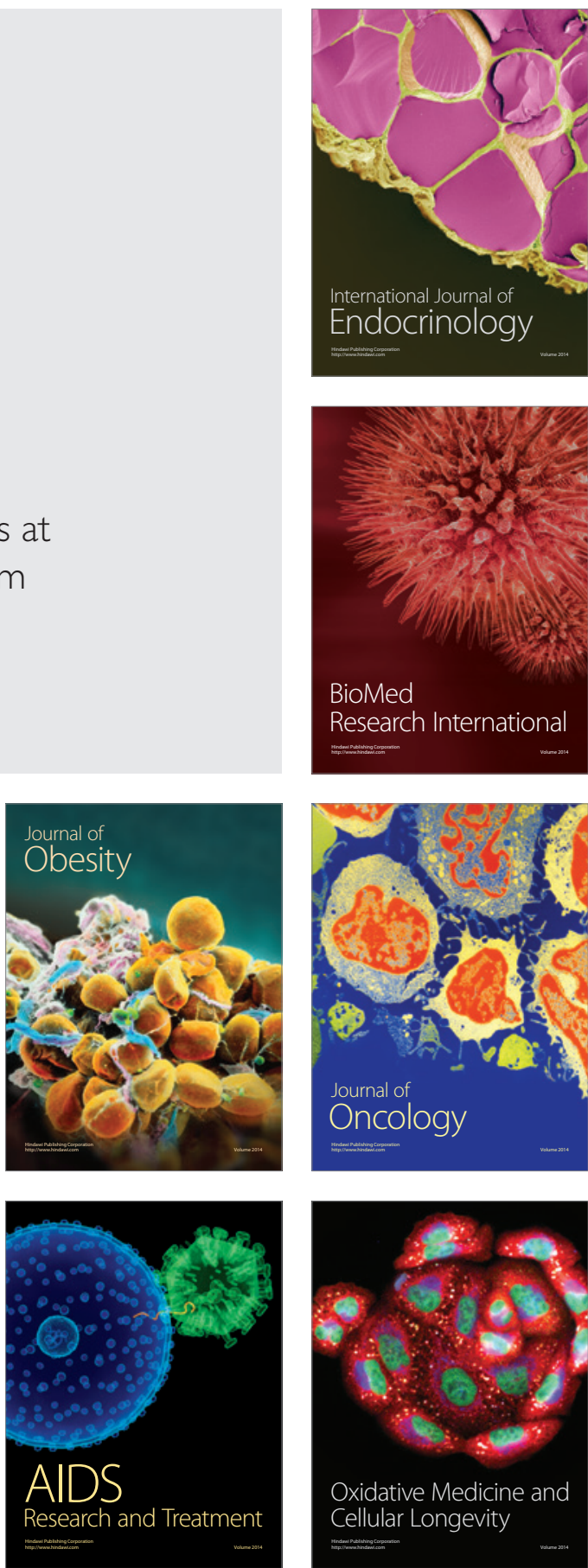